\title{
Tailoring of poly(vinyl alcohol) cryogels properties by salts addition
}

\author{
S. Paţachia ${ }^{*}$, C. Florea ${ }^{1}$, Chr. Friedrich ${ }^{2}$, Y. Thomann ${ }^{2}$ \\ ${ }^{1}$ Department of Chemistry, Transilvania University of Brasov, 29 Eroilor Street, 500036 Braşov, Romania \\ ${ }^{2}$ Rheology Department, Albert Ludwigs University of Freiburg, 21st Stefan-Meier, 79104 Freiburg, Germany
}

Received 9 February 2009; accepted in revised form 20 March 2009

\begin{abstract}
The present paper aims to study the possibility to modify the properties of poly(vinyl alcohol) (PVA) hydrogels prepared in the presence of different salt types $\left(\mathrm{Na}_{2} \mathrm{SO}_{4}, \mathrm{NaCl}\right.$ and $\left.\mathrm{NaNO}_{3}\right)$ in order to extend the nature of the salts already used in obtaining films or gels, to expand their concentration domains and to explain the increase of film strain, concomitantly with the increase of their crystallinity. The morphology of the PVA based hydrogels has been studied by Scanning Electronic Microscopy (SEM), the interaction between the PVA macromolecular chains and salts has been determined by Fourier Transform Infrared Spectroscopy (FTIR), while the mechanical properties of the cryogels have been investigated by oscillatory dynamic mechanical measurements. The gels swelling in water have been monitored by gravimetric method in order to evidence the alteration of the PVA cryogel properties such as crystallinity and porosity determined by the salt addition to the initial PVA aqueous solution. The data reported show that the ions present in the PVA solution influence the interaction between PVA-water and PVA-PVA chains; their influence on the salt-based PVA hydrogels follow the Hofmeister lyotropic series.
\end{abstract}

Keywords: rheology, tailored-made polymers, poly(vinyl alcohol) cryogel, salts, Hofmeister series

\section{Introduction}

PVA is a polymer with exceptional properties such as water solubility, biodegradability, biocompatibility, non-toxicity and non-carcinogenity that possesses the capability to form hydrogels by chemical or physical methods [1-6]. Its fields of applicability were widely broadened during the latest years due to the development of medicine and the increase of the needs in new biomaterials, to the introduction of new concepts in medication by creating the controlled drug release systems, to the environmental protection need, aiming at sustainable development by obtaining new ecological systems for water purification (membranes or absorbent materials), conductive systems for renewable energy sources, etc. [7-9]. PVA is a non-expensive and versatile polymer, adaptable to various needs with minor modifications of the synthetic procedures $[1,10]$. During the latest years many research groups focused their attention on the study of PVA films or gels obtained by the simple addition of salts to the aqueous PVA solution. Very interesting properties have been obtained. For example, the addition of $\mathrm{NaCl}$ to the PVA water solution and the freezing of the obtained solution at liquid nitrogen temperature led to the increase of the hydrogel crystallinity, and, as a consequence, to the increase of the rigidity modulus $G^{\prime}$ [11]. The same increase of the $G^{\prime}$ for PVA hydrogels obtained by freezing-thawing processes at $-20^{\circ} \mathrm{C} / 20^{\circ} \mathrm{C}$ has been evidenced by other researchers, corresponding to the relative swelling decrease [12]. PVA films prepared in the 
presence of $\mathrm{NaCl}$ led to obtaining insoluble films, showing an unusual combination of properties: higher crystallinity and simultaneously, higher draw ratio $[13,14]$. Moreover, high performance films have been obtained by casting PVA/ $/ \mathrm{Na}_{2} \mathrm{SO}_{4}$ (up to $0.05 \mathrm{wt} \%$ ) $/ \mathrm{H}_{2} \mathrm{O}$ or $\mathrm{PVA} / \mathrm{CH}_{3} \mathrm{COONa}$ (up to $0.1 \mathrm{wt} \%) / \mathrm{H}_{2} \mathrm{O}$ solutions, and removing the salts used from the films through a washing process. Both films obtained are water resistant due to their high crystallinity, and they concomitantly have high drawability and mechanical resistance values [15].

Bhargav et al. obtained polymer electrolyte films for the solid state battery development by doping PVA gels with $\mathrm{NaBr}$ [16]. The PVA electrolyte film prepared in the presence of $\mathrm{NaBr}$ evidenced a lower crystallinity value than the value corresponding to the neat films. Obtaining PVA films doped with $\mathrm{BaCl}_{2}$ has been reported by Bhajantri et al. [17]. A complex formation between $\mathrm{Ba}^{2+}$ ions and $\mathrm{OH}$ groups of PVA is considered to be responsible for the PVA film crystallinity increase. The dc and ac conductivities of the $\mathrm{BaCl}_{2}$ doped PVA films have been increased along with the increase of the doping agent concentration.

PVA hydrogels in contact with micro-molecular inorganic salts have also been studied, aiming at elucidating the osmotic properties of the cryogels during a long-lasting exposure to aqueous media, at establishing the gels' behaviour in contact with physiological liquids or at designing electrolyte sensors based on PVA hydrogel materials, which exhibit an intelligent behaviour in the presence of electrolyte solutions [18-24]. It has been reported that PVA hydrogels collapse when they come into contact with $\mathrm{NaCl}, \mathrm{KCl}, \mathrm{CsCl}, \mathrm{Na}_{3} \mathrm{PO}_{4}$ and $\mathrm{Na}_{2} \mathrm{SO}_{4}$ solutions; the gel's shrinking depends on the salt nature and concentration. The osmotic stability of the PVA hydrogels and the fact that they maintain their porous morphology during ageing have been evidenced. All these properties make the PVA cryogels a suitable material for cell immobilization and sensors design.

In this framework, our paper comes to extend the nature of the studied salts used for the PVA cryogel preparation $\left(\mathrm{Na}_{2} \mathrm{SO}_{4} \cdot 10 \mathrm{H}_{2} \mathrm{O}, \mathrm{NaCl}\right.$ and $\left.\mathrm{NaNO}_{3}\right)$ and to expand the concentration domains of the salts (25 wt\% with respect to PVA). The salt-based PVA hydrogels obtained have been characterized by visual methods, SEM, FTIR, rheological and gravimetric measurements. The solid content, equilibrium water content $(E W C)$ of the gels, the collapse kinetic when in contact with $0.5 \mathrm{M}$ $\mathrm{Na}_{2} \mathrm{SO}_{4} \cdot 10 \mathrm{H}_{2} \mathrm{O}$ solution, shrinking equilibrium, and the mechanism of water diffusion from the gels during their collapse have all been investigated. The analyses performed aimed at correlating the morphological alteration of the salt-based gels prepared with the nature of the salt used depending on its kosmotropic or chaotropic character.

This procedure enables us to obtain PVA cryogels with tailored properties by using very simple methods.

\section{Experimental}

\subsection{Materials}

The PVA used for this work was purchased in powder form, with industrial grades, from the Chemical Plant Râşnov (Romania) and it was used without any further purification. The polymer has a polymerization degree of 900, a saponification degree of $98 \%$ and a molecular weight of $48600 \mathrm{~g} / \mathrm{mol}$.

$\mathrm{Na}_{2} \mathrm{SO}_{4} \cdot 10 \mathrm{H}_{2} \mathrm{O}$ and $\mathrm{NaNO}_{3}$ were purchased from Reactivul Bucureşti (Romania), while $\mathrm{NaCl}$ was procured from Fluka (Germany). All the salts used during the current study had analytical reagent grades.

\subsection{Preparation of aqueous solutions}

a) A $12 \mathrm{wt} \%$ PVA aqueous solution was prepared in distilled water at $80^{\circ} \mathrm{C}$ under continuous magnetic stirring for 3 hours in a dust-free environment. The PVA solution obtained was chilled until it reached the room temperature, and it was filtered and divided in four equal parts. One part of the PVA solution was stored as obtained, and it was used for the neat PVA hydrogel preparation. The other three parts of the PVA solution prepared were split into equal volumes and further used for the preparation of the salt-based PVA solutions.

b) $0.5 \mathrm{M}$ sodium sulphate solution was prepared with distilled water, at ambient temperature, using $\mathrm{Na}_{2} \mathrm{SO}_{4}$ solid state with analytical grade purchased from Reactivul Bucureşti.

\subsection{Preparation of salt-based PVA solution}

In order to prepare salt-based PVA solutions, the same volumes of the previously synthesized PVA 
solution were mixed with $25 \mathrm{wt} \%$ (based on the PVA weight) of $\mathrm{NaCl}, \mathrm{Na}_{2} \mathrm{SO}_{4} \cdot 10 \mathrm{H}_{2} \mathrm{O}$ and respectively $\mathrm{NaNO}_{3}$ under continuously magnetically stirring at $80^{\circ} \mathrm{C}$ for 1 hour. After the complete dissolution of the salt into the PVA solution, three different salt-based PVA solutions have been obtained; the solutions were cooled until reaching the room temperature and filtered before further usage.

\subsection{Synthesis of salt-based PVA hydrogels}

$20 \mathrm{ml}$ from each $\mathrm{PVA} / \mathrm{H}_{2} \mathrm{O}$ obtained and respectively PVA/salt/ $\mathrm{H}_{2} \mathrm{O}$ solutions were cast in $10 \mathrm{~cm}$ diameter Petri dishes. The cast solutions were submitted to a 12 hours freezing at $-20^{\circ} \mathrm{C}$ and a 12 hours thawing at room temperature $\left(22^{\circ} \mathrm{C}\right)$. The submission of the samples to the freezing-thawing cycle has been performed thrice, until the solutions were converted to white and opaque hydrogels that exhibit good mechanical resistance.

At the end of the last thawing cycle, the obtained PVA hydrogels containing salts were soaked in distilled water in order to remove the salts used during the preparation process and the polymer that was not crosslinked during the freezing and thawing process; the procedure of distilled water exchanging for the PVA/ $\mathrm{H}_{2} \mathrm{O}$ and PVA/salt $/ \mathrm{H}_{2} \mathrm{O}$ hydrogels has been repeated every 24 hours for 7 days.

All the PVA hydrogels obtained were immersed in excess of distilled water in order to reach the swelling equilibrium for another 7 days.

\subsection{Methods}

\subsubsection{Gravimetry}

The monitoring of PVA/ $\mathrm{H}_{2} \mathrm{O}$ and PVA/salt $/ \mathrm{H}_{2} \mathrm{O}$ sample mass variation as a result of losing water during the immersion in electrolyte solution has been done gravimetrically, by using a Kern ABS/ ABJ balance which has a precision of $10^{-4} \mathrm{~g}$.

Samples weighing approximately $0.50-0.75 \mathrm{~g}$ were immersed in $100 \mathrm{ml}$ solution of $\mathrm{Na}_{2} \mathrm{SO}_{4}$, taken out of the solution at a previously predetermined time, gently blotted on filter paper for salt excess removal and weighed.

The percentage of water retained by the analyzed hydrogels at time $t$ after their immersion into the $\mathrm{Na}_{2} \mathrm{SO}_{4} \cdot 10 \mathrm{H}_{2} \mathrm{O} 0.5 \mathrm{M}$ electrolyte solution has been calculated on the basis of the Equation (1):
$\Delta m_{r e t}[\%]=\frac{m_{t}-m_{x}}{m_{x}} \cdot 100$

where $m_{t}$ represents the mass of the hydrogel at time $t$ after its immersion into the electrolyte solution, and $m_{x}$ is the mass of the dry gel [18].

\subsubsection{Scanning Electron Microscopy}

The characterization of $\mathrm{PVA} / \mathrm{H}_{2} \mathrm{O}$ and $\mathrm{PVA} / \mathrm{salt} /$ $\mathrm{H}_{2} \mathrm{O}$ hydrogels was performed by using an Environmental Scanning Electron Microscope. Metal sample coating was done with a Polaron SC 7640 ion sputter coating instrument, at a $1.5 \mathrm{kV}$ voltage.

\subsubsection{Fourier Transform Infrared (FT-IR) spectroscopy}

The neat PVA sample and the PVA hydrogels that reached the shrinking equilibrium in the presence of different aqueous salt solutions were subjected to FTIR spectroscopy in the range of 4000 and $600 \mathrm{~cm}^{-1}$, using a Perkin-Elmer spectrophotometer. Prior to the measurement execution, the $\mathrm{PVA} / \mathrm{H}_{2} \mathrm{O}$ and PVA/salt $/ \mathrm{H}_{2} \mathrm{O}$ hydrogels have been vacuum dried overnight until no weight change has been evidenced.

\subsubsection{Rheometry}

The rheological experiments were performed using a Paar Physica UDS200 rheometer. The geometry used was a $25 \mathrm{~mm}$ diameter steel plate. All rheometry measurements were carried out using a disc shape sample with a diameter of $25 \mathrm{~mm}$ and an average thickness of $1.5 \mathrm{~mm}$. The storage and loss modulus characteristic to the different studied hydrogels as well as their viscosity were determined at a constant temperature of $25^{\circ} \mathrm{C}$.

\section{Results and discussion}

The visual observation of the PVA cryogels obtained in the presence of different salts led to the conclusion that the gels' transparency could be tailored by modifying the nature of the salt added to the PVA solution (Figure 1). The transparency of the gel is a very important property for the PVA based cryogels used for ocular medical devices or sensor design. Transparent PVA cryogels have 


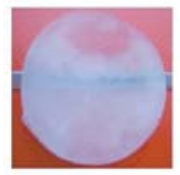

a)

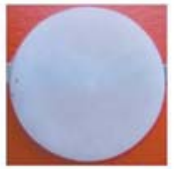

b)

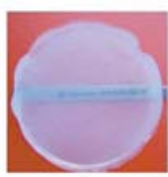

c)

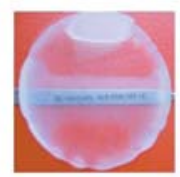

d)

Figure 1. Visual aspect of the PVA cryogels obtained in the presence of different salts, after their washing. a) $\mathrm{PVA} / \mathrm{H}_{2} \mathrm{O}$, b) $\mathrm{PVA} / \mathrm{Na}_{2} \mathrm{SO}_{4} / \mathrm{H}_{2} \mathrm{O}$, c) $\mathrm{PVA} / \mathrm{NaCl} / \mathrm{H}_{2} \mathrm{O}$, d) $\mathrm{PVA} / \mathrm{NaNO}_{3} / \mathrm{H}_{2} \mathrm{O}$

already been obtained using dimethyl sulfoxide (DMSO) as solvent [25], but DMSO is a toxic volatile solvent. The modification of the gel thickness represents another procedure used to obtain transparent PVA gels, but this method has limited applicability by the decrease in membrane mechanical resistance.

Using different salts in obtaining cryogel and removing them by washing with distilled water is a very easy method for tailoring PVA cryogel membrane transparency that does not involve toxic substances and keeps the needed membrane dimensions, and, as a consequence, their mechanical resistance.

As depicted in Figure 1, PVA/ $/ \mathrm{Na}_{2} \mathrm{SO}_{4} / \mathrm{H}_{2} \mathrm{O}$ cryogels are opaque, exhibiting a more heterogeneous structure when comparing with the $\mathrm{PVA} / \mathrm{H}_{2} \mathrm{O}$ cryogel. PVA $/ \mathrm{NaCl} / \mathrm{H}_{2} \mathrm{O}$ cryogels are more translucent, while the $\mathrm{PVA} / \mathrm{NaNO}_{3} / \mathrm{H}_{2} \mathrm{O}$ cryogels have a higher transparency than the neat PVA gel, evidencing a homogeneous structure.

As it is already known, PVA cryogels are obtained by polymer crystallization, crystallites playing the role of the crosslinking agent [26]. Differences in cryogel transparency could be correlated to obtaining different gel morphology, due to the influence of the salts on the solution characteristics, and due to the specific interactions between the ions coming from the salts dissociation, water molecules and PVA chains.

SEM images evidenced higher morphological differences between the cryogels obtained in the presence of different salts, as it is illustrated in Figure 2. The addition of $\mathrm{Na}_{2} \mathrm{SO}_{4}$ to the initial PVA solution determined the formation of a cryogel with a more compact structure with less interconnected pores, by comparison with the structure of the neat PVA cryogel. On the other hand, the addition of $\mathrm{NaCl}$ and $\mathrm{NaNO}_{3}$ respectively, determined the increase in gel porosity. In the presence of $\mathrm{NaCl}$, a gel with

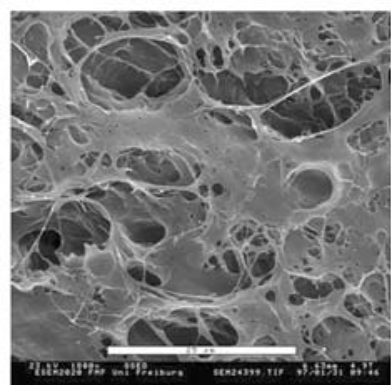

a)

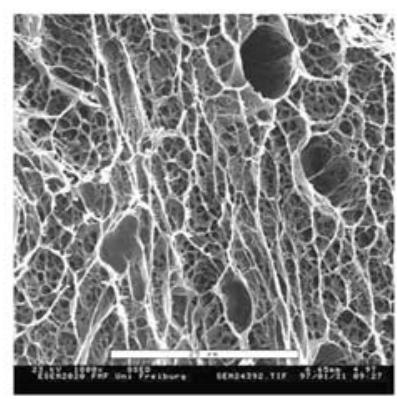

c)

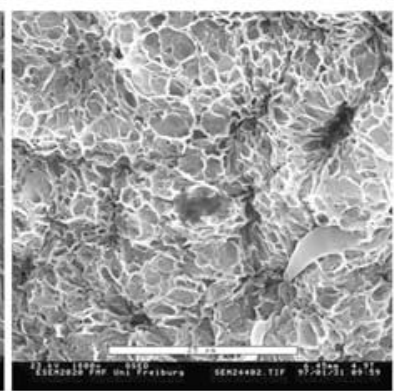

b)
Figure 2. SEM images of PVA hydrogels obtained, for a magnification of $1800 \times$. a) $\mathrm{PVA} / \mathrm{H}_{2} \mathrm{O}$,

b) $\mathrm{PVA} / \mathrm{Na}_{2} \mathrm{SO}_{4} / \mathrm{H}_{2} \mathrm{O}$, c) PVA/ $/ \mathrm{NaCl} / \mathrm{H}_{2} \mathrm{O}$,

d) $\mathrm{PVA} / \mathrm{NaNO}_{3} / \mathrm{H}_{2} \mathrm{O}$

a very large distribution of the pore dimensions and shapes has been obtained. Some elongated structures could be observed in the SEM image recorded for this hydrogel. $\mathrm{NaNO}_{3}$ presence during the PVA cryogel formation determined the obtaining of a gel with small pores that have a uniform size and shape distribution.

The FTIR spectroscopy has been used for the characterization of the interaction between the PVA macromolecular chains and salts. The spectra of all the prepared PVA hydrogels are shown in Figure 3, where the major absorption bands related to the hydroxyl and acetate groups are evidenced. The

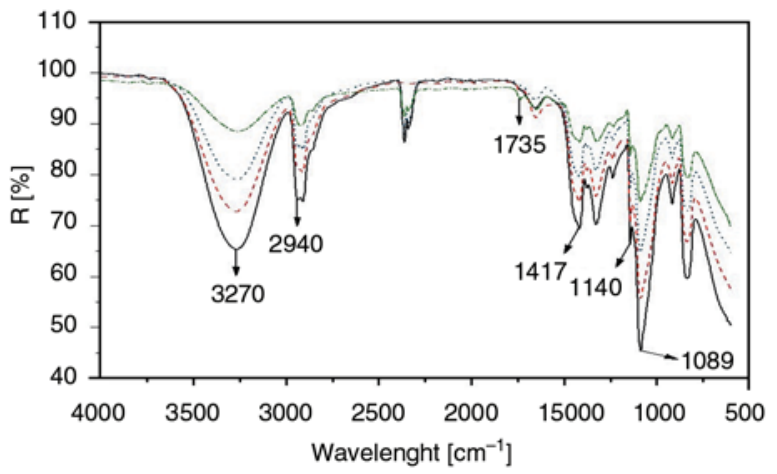

Figure 3. FTIR spectra characteristic to the PVA and PVA/salts cryogels: (-) PVA, $(---) \mathrm{PVA}+\mathrm{Na}_{2} \mathrm{SO}_{4},(\bullet \bullet) \mathrm{PVA}+\mathrm{NaCl}$ and $(-\bullet-\bullet) \mathrm{PVA}+\mathrm{NaNO}_{3}$ 
absorption band obtained in the range of 3600 and $3200 \mathrm{~cm}^{-1}$ is linked to the $-\mathrm{OH}$ groups involved in the intramolecular and intermolecular hydrogen bonds. The absorption band shown on the FTIR spectra in the range of 2840 to $3200 \mathrm{~cm}^{-1}$ corresponds to the $\mathrm{C}-\mathrm{H}$ bond from alkyl groups, and the band between 1700 and $1750 \mathrm{~cm}^{-1}$ is characteristic to the stretching $\mathrm{C}=\mathrm{O}$ from the acetate groups remained in the PVA during its obtaining. No new absorption bands or band shifting are present on the FTIR spectra of the cryogels, showing that no chemical interactions between PVA and the used salts occurred.

The FTIR analysis enabled us to obtain information concerning the cryogel crystallinity based on the band intensity ratio of $1141 \mathrm{~cm}^{-1}: 1096 \mathrm{~cm}^{-1}$ [27].

The ratio of absorption bands intensities (height) of the 1141 and $1096 \mathrm{~cm}^{-1}$ band has been determined for the neat PVA hydrogels as well as for the $\mathrm{PVA} / \mathrm{salt}$ hydrogels prepared. The addition of salt to the PVA solution during the hydrogel sample preparation caused an increase of the PVA/salt/ $\mathrm{H}_{2} \mathrm{O}$ crystallinity. This result is in agreement with other literature reports $[13-15,17,28]$ and could be correlated to the cryoscopy, determined by the presence of the salts in the aqueous solution of PVA. The decrease of the solution freezing point determines an increase in the period of macromolecules staying in the liquid phase, and, as a consequence, they could move, reorganize themselves and interact for a longer period, leading to higher crystalline domains. By comparing the hydrogel crystallinity as a function of the salt nature, it could be observed that the $\mathrm{PVA} / \mathrm{Na}_{2} \mathrm{SO}_{4} / \mathrm{H}_{2} \mathrm{O}$ hydrogels have the highest value of crystallinity (0.544), being followed by the $\mathrm{PVA} / \mathrm{NaCl} / \mathrm{H}_{2} \mathrm{O}$ hydrogels (0.530); the lowest crystallinity value obtained belongs to PVA/ $/ \mathrm{NaNO}_{3} / \mathrm{H}_{2} \mathrm{O}$ hydrogels (0.496). This hierarchy could be also correlated with the position of the used salts in the Hofmeister series [29-31]. Higher interaction between the macromolecular chains could occur due to the capacity of the sulphate ions of the kosmotropic type to take out the water from the polymeric gel (salting-out effect). In the particular case of PVA, this means an increase in $\mathrm{H}$ bonding generation. The lowest value of the crystallinity determined for the PVA/ $\mathrm{NaNO}_{3} /$ $\mathrm{H}_{2} \mathrm{O}$ hydrogels could be explained by the chaotropic character of $\mathrm{NO}_{3}^{-}$ions. The $\mathrm{NaNO}_{3}$ based PVA hydrogels lower interaction with water molecules
Table 1. Content of solid matter and equilibrium water content determined for PVA/ $\mathrm{H}_{2} \mathrm{O}$ and PVA/salt/ $\mathrm{H}_{2} \mathrm{O}$ hydrogels

\begin{tabular}{|c|l|r|c|}
\hline Crt. Nr. & \multicolumn{1}{|c|}{ Hydrogel type } & CS [\%] & EWC \\
\hline 1 & PVA/ $/ 2 \mathrm{O}$ & 8.16 & 0.9184 \\
\hline 2 & $\mathrm{PVA} / \mathrm{Na}_{2} \mathrm{SO}_{4} / \mathrm{H}_{2} \mathrm{O}$ & 10.52 & 0.8948 \\
\hline 3 & $\mathrm{PVA} / \mathrm{NaCl}_{2} \mathrm{O}$ & 8.26 & 0.9173 \\
\hline 4 & $\mathrm{PVA} / \mathrm{NaNO}_{3} / \mathrm{H}_{2} \mathrm{O}$ & 8.10 & 0.9189 \\
\hline
\end{tabular}

allow them to interact with $\mathrm{OH}$ groups of PVA, determining the decrease of the polymer-polymer chain interaction, and, as a consequence, a lower polymer crystallinity value is obtained.

The interaction between the PVA chains, determined by the addition of $\mathrm{Na}_{2} \mathrm{SO}_{4}$ to the initial PVA aqueous solution, is so strong that, after the salt release from the cryogel matrix, the swelling degree of the salt-based cryogel will never reach the swelling degree of the neat PVA cryogel.

This aspect can be evidenced by the gel solid content (CS) and the equilibrium water content (EWC) determined after the reaching of their swelling equilibrium (Table 1). The concentration in solid matter for each of the prepared hydrogels has been determined after the complete removal of the salt from the hydrogels prepared in the presence of salts, using Equation (2):

$$
\mathrm{CS}[\%]=\frac{m_{x}}{m_{w e}} \cdot 100
$$

where $m_{w e}$ represents the equilibrium mass of the swollen hydrogel in water and $m_{x}$ represents the mass of the dried gel (xerogel) [18].

For all the prepared hydrogels the content of water at their equilibrium state (EWC) has also been determined as the ratio between the mass of the water contained by the hydrogel at the swelling equilibrium and the mass of the xerogel. The EWC values have been calculated in order to compare the water content of the prepared cryogels at their equilibrium state with the EWC value of the human body cells. For all the PVA based hydrogels prepared, the EWC values are higher than the cell EWC value (0.6) [32], evidencing the suitability of these cryogels to be used in the biomaterial field. The highest CS value and the lowest EWC value obtained for the PVA cryogels prepared in the presence of $\mathrm{Na}_{2} \mathrm{SO}_{4}$ are in total agreement with the SEM analysis results. The relative small variation of the CS and EWC determined for the prepared 
PVA and PVA salt-based cryogels follows the same rule as the gel transparency, SEM images and crystallinity modification.

The cryogel transparency increase (following the order: $\mathrm{Na}_{2} \mathrm{SO}_{4}, \mathrm{NaCl}$ and $\mathrm{NaNO}_{3}$ ) corresponds to the decrease in the cryogel crystallinity, their compactness decrease, the decrease of the solid content and the EWC increase.

Taking into account that the mechanical properties of the gels are closely related to the gel's crystallinity (crosslinking), the mechanical behaviour of the PVA/ $\mathrm{H}_{2} \mathrm{O}$ and PVA/salt $/ \mathrm{H}_{2} \mathrm{O}$ hydrogels has been studied by oscillatory dynamic mechanical measurements. Figure 4 presents the frequency dependency of both storage $\left(G^{\prime}\right)$ and loss $\left(G^{\prime \prime}\right)$ moduli for the neat and salt-based PVA hydrogels prepared by freezing and thawing techniques, at a constant strain of $1 \%$.

The frequency sweep experiments evidenced that both the storage modulus $G^{\prime}$ and the loss modulus $G^{\prime \prime}$ are not dependent on the frequency variation between 0.1 and $10 \mathrm{~Hz}$. The comparative analysis of $G^{\prime}$ and $G^{\prime \prime}$ values obtained by using the rheological experiments evidences that $G^{\prime}$ is considerably higher than $G^{\prime \prime}$, showing the solid-like behaviour of the studied gels in agreement with the existence of a network structure.

Both moduli, $G^{\prime}$ and $G^{\prime \prime}$, are highly dependent on the hydrogel type studied. As depicted in Figure $4 \mathrm{a}$ ), the PVA/ $\mathrm{Na}_{2} \mathrm{SO}_{4} / \mathrm{H}_{2} \mathrm{O}$ hydrogels have the highest storage modulus, which evidence a higher crosslinking density comparing to all the other hydrogels analyzed, due to the higher interaction of the polymer chains as consequence of salting out phenomenon. The comparative analysis of the storage modulus specific to $\mathrm{PVA} / \mathrm{NaCl} / \mathrm{H}_{2} \mathrm{O}$ and PVA/ $\mathrm{NaNO}_{3} / \mathrm{H}_{2} \mathrm{O}$ hydrogels evidences minor differences between the crosslinking densities.

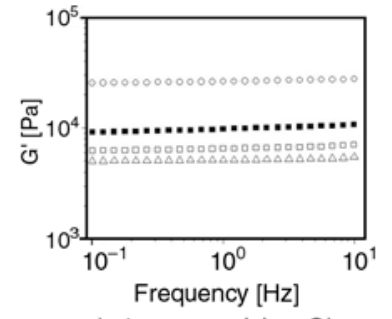

a) storage modulus, $\mathrm{G}^{\prime}$

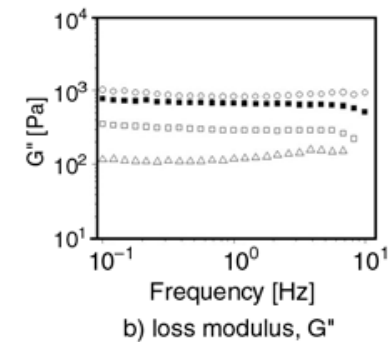

b) loss modulus, G"
Figure 4. Modulus dependency as a function of the frequency, at $1 \%$ deformation (घ) PVA,

(o) $\mathrm{PVA}+\mathrm{Na}_{2} \mathrm{SO}_{4},(\Delta) \mathrm{PVA}+\mathrm{NaCl}$ and

(口) $\mathrm{PVA}+\mathrm{NaNO}_{3}$

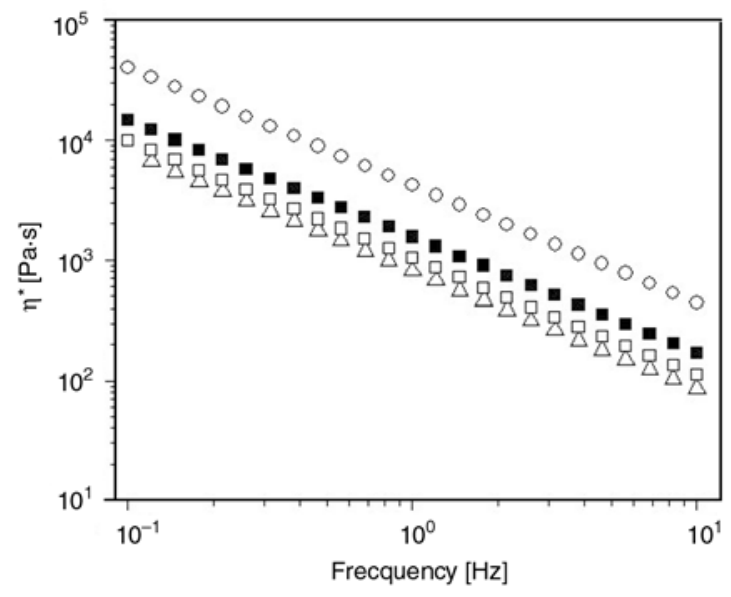

Figure 5. Viscosity dependency of different types of PVA hydrogels on the frequency ( $\square)$ PVA,

(o) $\mathrm{PVA}+\mathrm{Na}_{2} \mathrm{SO}_{4},(\Delta) \mathrm{PVA}+\mathrm{NaCl}$ and

() $\mathrm{PVA}+\mathrm{NaNO}_{3}$

The viscosity dependency of neat and salt-based PVA hydrogels on the frequency sweep is depicted in Figure 5. The graphical representation illustrates that the viscosity is decreasing proportionally to the frequency increase for all the analyzed samples.

These rheological results obtained are in agreement with the Hofmeister series and with our abovementioned data, obtained by gravimetrical, SEM and FTIR measurements.

Figure 6 shows the strain dependence of the storage modulus at a constant frequency of $1 \mathrm{~Hz}$ for different types of synthesized hydrogels. At low strain amplitudes, the storage modulus $G^{\prime}$ is not dependent on the strain variation; this behaviour indicates that the deformations imposed to the network structure of all the studied types of hydrogels are

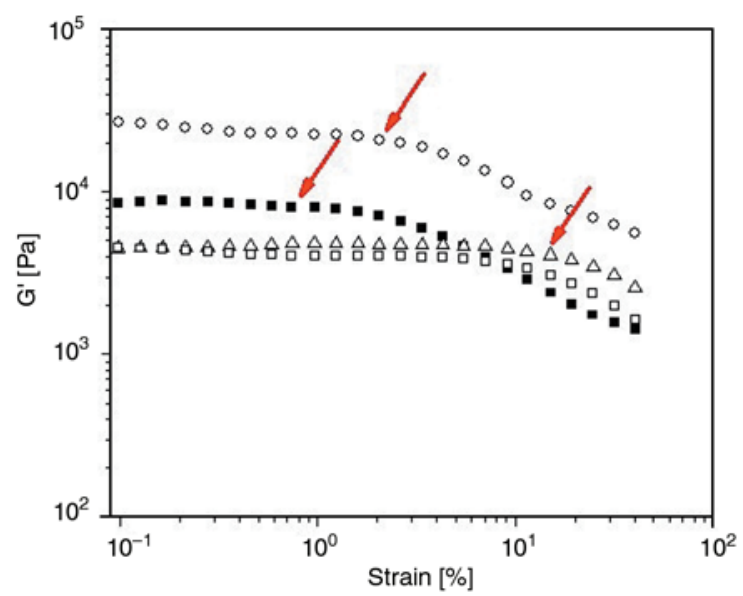

Figure 6. Storage modulus $G^{\prime}$ variation as function of strain amplitude, at $1 \mathrm{~Hz}$ constant frequency (匹) PVA, (o) $\mathrm{PVA}+\mathrm{Na}_{2} \mathrm{SO}_{4},(\Delta) \mathrm{PVA}+\mathrm{NaCl}$ and (口) $\mathrm{PVA}+\mathrm{NaNO}_{3}$ 
entirely reversible. Contrary, at high values of strain amplitude, the $G^{\prime}$ of the studied samples is decreasing with the increase of strain amplitude, indicating that the deformation is no longer reversible.

From the rheological measurement obtained, it can be observed that the domain of reversibility for the gel deformation is higher if more chaotropic salts are used (such as $\mathrm{NaCl}$ and $\mathrm{NaNO}_{3}$ ) and lower if kosmotropic salts are used $\left(\mathrm{Na}_{2} \mathrm{SO}_{4}\right)$. Furthermore, it is obvious that all the salts determine the increase of the domain of elastic behaviour for the salt-based PVA cryogels in comparison to the domain of elastic behaviour specific to the neat PVA cryogel. Usually, a higher crystallization degree results in a more rigid structure. In this case, the formation of more compact structures in the presence of salts could be due to crystallization, polymer chain interaction in the amorphous phase as well as to chain entanglement repartition between the crystalline domains. A higher kosmotropic effect leads to stronger amorphous phase chain interaction, and, consequently, lower elasticity. The more chaotropic the salts, the lower the interaction in the amorphous phase, leading to more elastic gel behaviour.

To compare the rheological behaviour of the PVA hydrogels prepared in the presence of different salts, the values of the sample storage modulus, $G_{\text {sample }}^{\prime}$, have been normalized by the storage modulus characteristic for the $\mathrm{PVA} / \mathrm{H}_{2} \mathrm{O}$ hydrogel.

The normalized storage modulus has been calculated using the Equation (3):

$\Delta G=\frac{G_{\text {sample }}^{\prime}}{G_{P V A \text { hydrogel }}^{\prime}}$

where $G_{\text {sample }}^{\prime}$ represents the storage modulus of the analyzed neat or salts based PVA hydrogels, and $G_{P V A}^{\prime}$ hydrogel represents the value of the storage modulus characteristic of the $\mathrm{PVA} / \mathrm{H}_{2} \mathrm{O}$ hydrogelic matrix.

The normalized storage modulus at $1 \%$ deformation for the various types of hydrogels studied by rheological measurements at a constant frequency of $1 \mathrm{~Hz}$ is illustrated in Figure 7.

As shown in the Figure 7, the PVA/ $/ \mathrm{Na}_{2} \mathrm{SO}_{4} / \mathrm{H}_{2} \mathrm{O}$ hydrogel has a higher normalized storage modulus than the neat PVA hydrogel; this is due to the increase in the interaction between the polymeric chains, both in the crystalline and amorphous

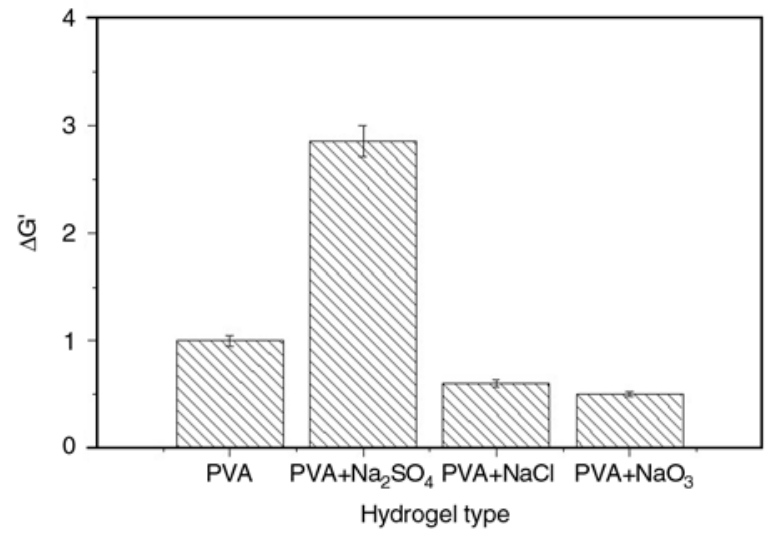

Figure 7. Normalized storage modulus $\Delta G^{\prime}$ variation depending on the PVA hydrogel type $(v=1 \mathrm{~Hz}$ and $\gamma=1 \%$ )

phases, determined by the capacity of the kosmotrope sulphate ions to make the water structure. The hierarchy of the normalized $G^{\prime}$ variation with the salts' nature is in agreement with the lyotropic Hofmeister series and our above mentioned results. But, comparing the $\Delta G^{\prime}$ values of the salt-based PVA hydrogels and simple PVA hydrogel, we can say that higher values of $\Delta G^{\prime}$ are expected for all the hydrogels prepared in the presence of salts due to their higher crystallinity. In the case of $\mathrm{NaCl}$ and $\mathrm{NaNO}_{3}$ use, the graphical representation shows that $\Delta G^{\prime}$ values are lower than the value corresponding to the PVA hydrogel. This aspect evidences that the crystallinity degree controls the mechanical characteristics of the gel, the repartition of the crystallites as well as the chain interaction in the amorphous phase. It is possible that a higher interaction between the polymer chains occurs due the fast elimination of the water molecules from the network of the gels, as a result of the stronger kosmotropic character manifested by the added salt; the higher polymer chain interaction leads to a higher number of entanglements of polymeric chains entrapped between the former growing up crystallites. This fact contributes to the increase of the $G^{\prime}$ maintaining the same value for the elasticity of the gel. In the presence of the more chaotropic ions, only a part of the water molecules are structured around them, the other part interacting with the polymer chains. The lower gel's collapse facilitates the crystallite growth and chain entanglements are avoided. In this manner, the effect of the smaller increase of the gel's crystallinity could be balanced by the water molecules retained into the gel. The first factor, crystallinity, determines the 

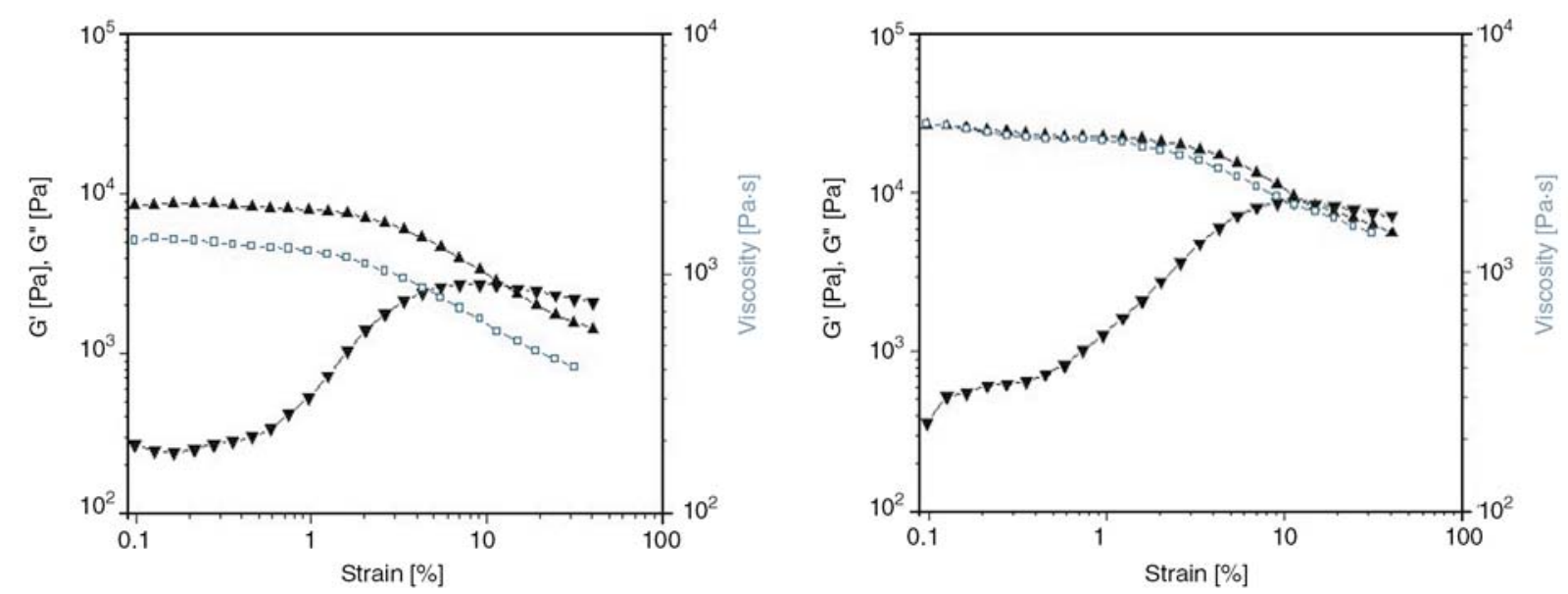

a) PVA hydrogel

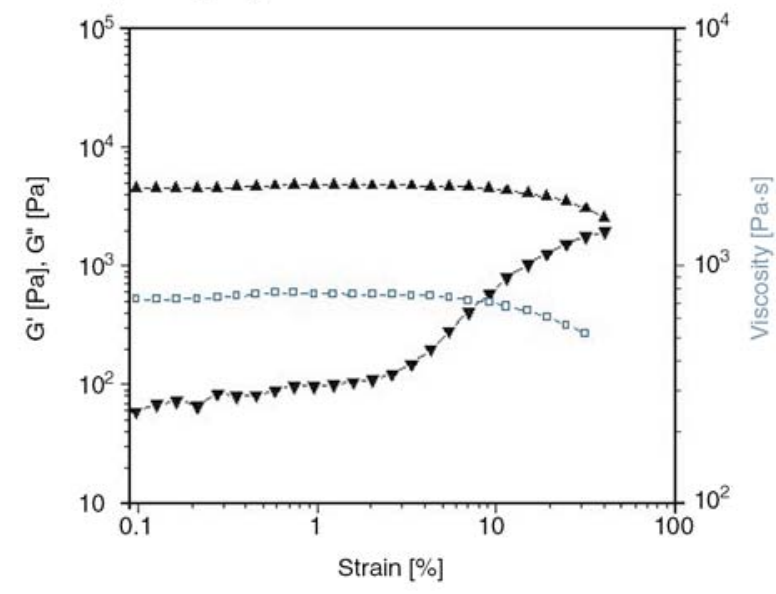

c) $\mathrm{PVA}+\mathrm{NaCl}$ hydrogels

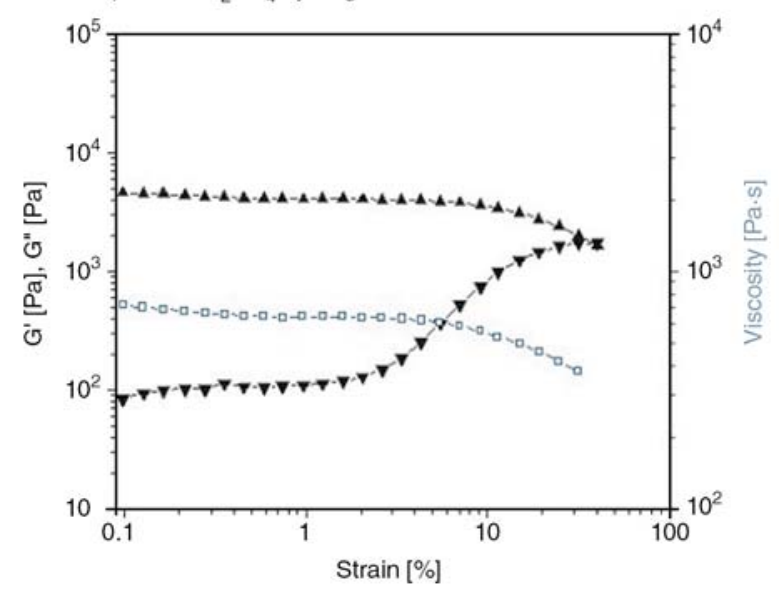

d) $\mathrm{PVA}+\mathrm{NaNO}_{3}$ hydrogels

Figure 8. Rheological parameters variation as a function of strain $(\boldsymbol{\Delta})$ storage modulus $G^{\prime},(\boldsymbol{\nabla})$ loss modulus $G^{\prime \prime}$ and (口) viscosity $\eta$

increase of $G^{\prime}$, while the second factor, the water molecules, determines the $G^{\prime}$ value decrease due to the plastifying character exhibited by the water. The stronger the chaotropic ions, the lower the $G^{\prime}$ value of the gels.

This aspect has been followed by the determination of the critical modulus $G_{x}^{\prime}$ and critical strain $\gamma_{x}$ values from the junction point of the two curves that characterise the $G^{\prime}$ and the $G^{\prime \prime}$ variation as function of the strain amplitude (Figure 8).

Regardless of the nature of the hydrogels studied, at lower strain amplitudes, the loss modulus values are lower than the storage modulus values, in total agreement with the existence of a network structure. The graphical representation in Figure 8 shows that, for small strain values, the storage modulus of the neat and salt-based PVA hydrogels is not dependent on the strain amplitude. This behaviour evidences that the deformation imposed on the network structure is entirely reversible. The increase of the strain amplitude applied above the critical value induces the liquid like behaviour of the gels that means irreversible deformation, evidenced by the decrease of the storage modulus and the increase of the loss modulus.

In Figure 9 the dependence of $G_{x}^{\prime}$ and $\gamma_{x}$ on the salt nature is plotted.

The graphical representation illustrates that the $G_{x}^{\prime}$ values corresponding to the neat PVA cryogel and to the cryogels prepared in the presence of chaotropic salts are very close, while the $G_{x}^{\prime}$ value of the gel prepared in the presence of kosmotropic ions is significantly higher. The interesting part is the influence of the chaotropic salts on the elasticity domain of the gels: stronger chaotropic ions extend the elasticity domain even if the gel crystallinity increased. This could be an explanation and a validation for the behaviour of the PVA/ $\mathrm{NaCl} / \mathrm{H}_{2} \mathrm{O}$ hydrogels that exhibit a simultaneous increase in crystallinity and drawability. 

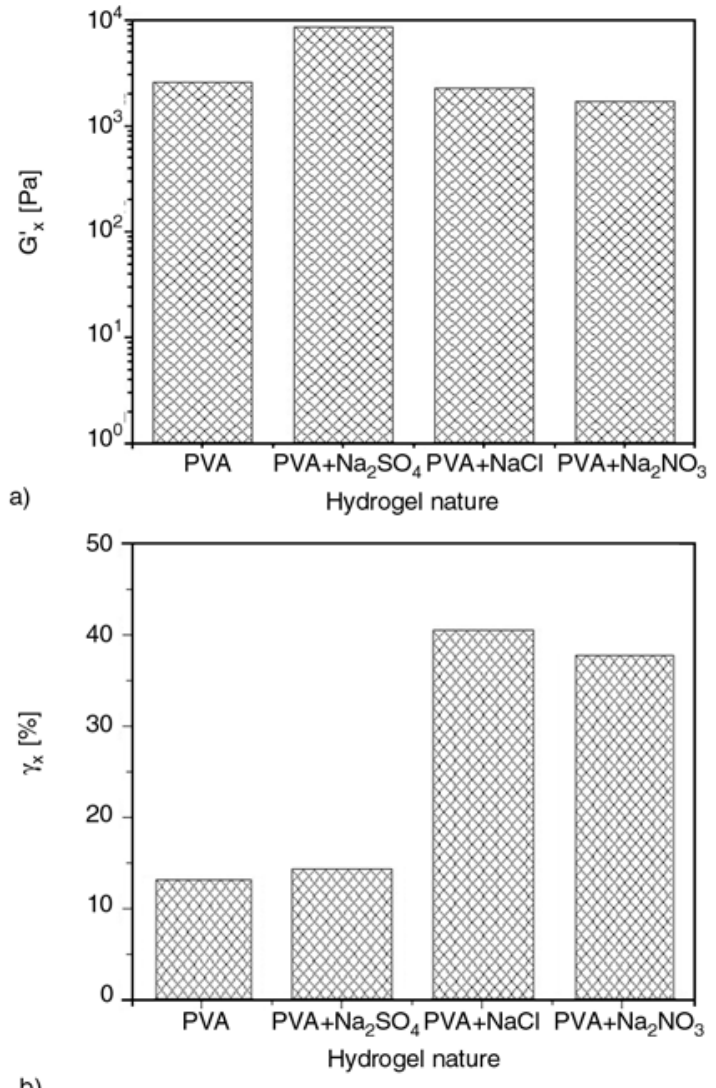

b)

Figure 9. The variation of the critical modulus and the critical deformation as a function of the PVA hydrogel nature

This aspect could also be related to the hydrogel morphology: a higher porosity of the gel leads to a higher water content at swelling equilibrium. The rheological properties of the gels are influenced by their water content as well as by their crosslinking degree (crystallinity). $\mathrm{NaCl}$ and $\mathrm{NaNO}_{3}$ use for hydrogel preparation leads to an increase in gel porosity, an increase of water content, and, consequently, a decrease in the $\Delta G^{\prime}$ by comparison with the neat PVA hydrogel.

The alteration of the PVA cryogel crystallinity and porosity determined by the salt addition to the initial PVA aqueous solution influences the mechanical active behaviour of cryogels when in contact with electrolyte solutions.

In order to evidence this influence, the behaviour of $\mathrm{PVA} / \mathrm{H}_{2} \mathrm{O}$ and PVA/salt $/ \mathrm{H}_{2} \mathrm{O}$ hydrogels in the presence of sodium sulphate aqueous solution has been studied using a gravimetric method.

Figure 10 depicts the variation in time of the amount of water retained by the different types of analyzed cryogels as result of their contact with the $0.5 \mathrm{M}$ salt solution.

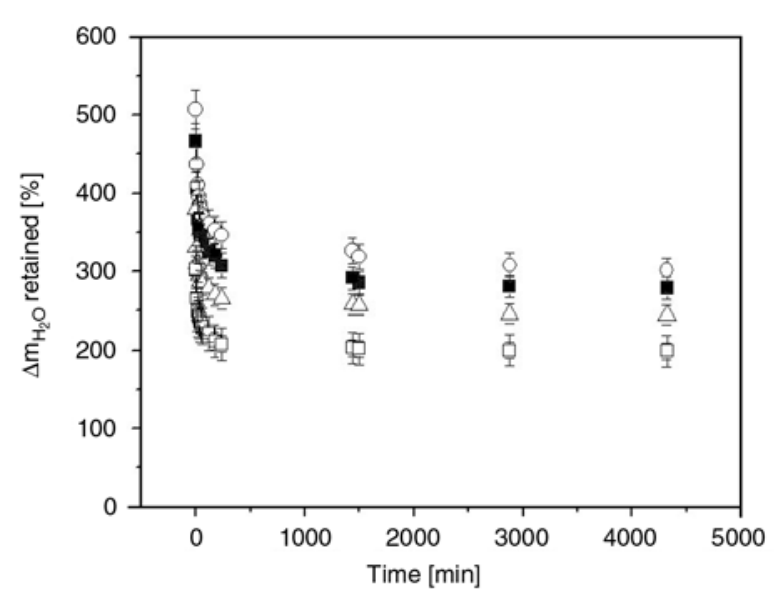

Figure 10. The variation of water retained percentage as function of time and he nature of the hydrogel during immersion in $0.5 \mathrm{M} \mathrm{Na}_{2} \mathrm{SO}_{4} \cdot 10 \mathrm{H}_{2} \mathrm{O}$,

(匹) PVA, (o) PVA/ $/ \mathrm{Na}_{2} \mathrm{SO} 4 / \mathrm{H}_{2} \mathrm{O}$,

( $\Delta$ ) PVA/NaCl/ $/ \mathrm{H}_{2} \mathrm{O}$ and ( $\square$ ) $\mathrm{PVA} / \mathrm{NaNO}_{3} / / \mathrm{H}_{2} \mathrm{O}$

The contact with the $\mathrm{Na}_{2} \mathrm{SO}_{4}$ aqueous solution of the different types of hydrogels prepared determines their collapse. It is obvious that the percentage of the water retained by the neat PVA hydrogel as well as by the PVA hydrogels prepared in the salt presence is significantly decreasing on the first interval of analysis ( 0 to 500 minutes), due to the elimination of water initially absorbed by the samples studied during the swelling process. After approximately 1500 minutes of contact between the sodium sulphate solution and the hydrogels, the changing of the sample mass is not significant as a result of reaching the shrinking equilibrium; a plateau is reached, as depicted in the graphical representation in Figure 10.

It can be observed that the highest collapse is obtained for the PVA/ $/ \mathrm{NaNO}_{3} / \mathrm{H}_{2} \mathrm{O}$ cryogels, while the lowest is evidenced for the PVA/ $/ \mathrm{Na}_{2} \mathrm{SO}_{4} / \mathrm{H}_{2} \mathrm{O}$ cryogels. This behaviour is in agreement with the above-mentioned cryogel characteristics. PVA/ $\mathrm{NaNO}_{3} / \mathrm{H}_{2} \mathrm{O}$ cryogels, with a very porous structure, having a higher contact surface with the salt solution, and being less crystalline, exhibit a stronger collapse. PVA/ $/ \mathrm{Na}_{2} \mathrm{SO}_{4} / \mathrm{H}_{2} \mathrm{O}$ cryogels exhibit a lower collapse because they are more compact and have a higher crystallinity.

The mechanism of water diffusion from the cryogels during their shrinking process and the rate of the water release from their network structure are also dependent on the cryogels' morphology; the waters diffusion mechanism could be tailored by using different salts for the PVA cryogel preparation. 
The mechanism of water diffusion during the shrinking process in $\mathrm{Na}_{2} \mathrm{SO}_{4}$ aqueous solution has been analyzed using the Equation (4):

$$
1-\frac{M_{t}}{M_{w e}}=k \cdot t^{n}
$$

where $M_{t}$ represents the weight of the samples at the time $t$ after their immersion into the electrolyte aqueous solution, $M_{w e}$ is the mass of the hydrogels at its swelling equilibrium, $k$ represents the constant that characterized the three dimensional, reticulated hydrogel network, and the $n$ parameter is the exponential coefficient that describes the type of the water diffusion mechanism [33-36].

Linear dependencies $\left(\ln \left(1-M_{t} / M_{e}\right)=b+a \cdot \ln t\right)$ have been obtained in double logarithmic coordinates for all the samples collapsed, as it could be seen in Figure 11.

The fitting parameters corresponding to the water diffusion from the hydrogel matrix are depicted in the table displayed below (Table 2).

The calculation of the kinetic slopes allowed determining the $n$ values, which characterize the mechanism of water diffusion from the studied polymeric network. The values obtained for the $n$ parameter, in the range of 0.20 to 0.25 , evidenced a non-Fickian diffusion of water from all the hydrogel types studied ( $\mathrm{PVA} / \mathrm{H}_{2} \mathrm{O}$ and $\left.\mathrm{PVA} / \mathrm{salt} / \mathrm{H}_{2} \mathrm{O}\right)$, during their immersion into an aqueous solution of $\mathrm{Na}_{2} \mathrm{SO}_{4}$. As it is illustrated in Table 2 the slopes of the curves are dependent on the studied hydrogel type.

The low values for the $n$ parameter have been obtained due to the lower concentration of the start-

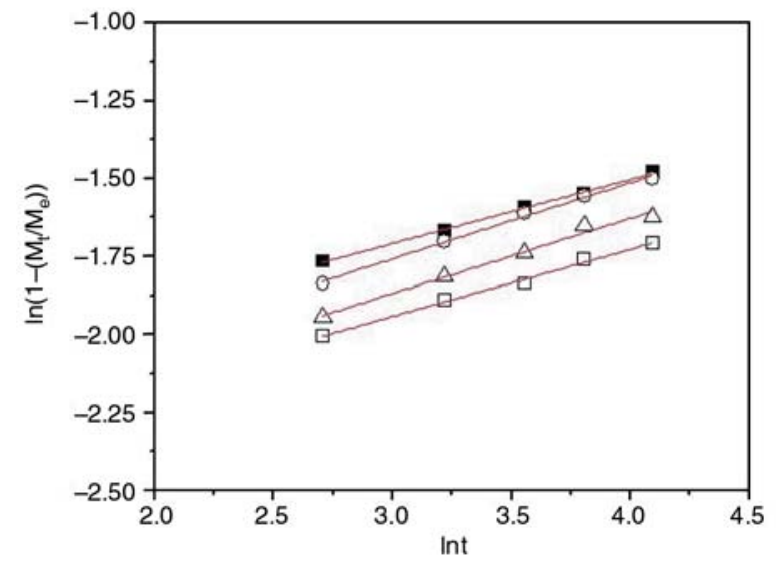

Figure 11. Dynamic kinetic variation of water diffusion from different types of hydrogels in the presence of $0.5 \mathrm{M} \mathrm{Na}_{2} \mathrm{SO}_{4} \cdot 10 \mathrm{H}_{2} \mathrm{O}$, (匹) PVA,

(o) $\mathrm{PVA}+\mathrm{Na}_{2} \mathrm{SO}_{4},(\Delta) \mathrm{PVA}+\mathrm{NaCl}$ and

() $\mathrm{PVA}+\mathrm{NaNO}_{3}$
Table 2. Fitting parameters of water diffusion from PVA/ $\mathrm{H}_{2} \mathrm{O}$ and PVA/salt $/ \mathrm{H}_{2} \mathrm{O}$ hydrogels in the presence of $0.5 \mathrm{M} \mathrm{Na}_{2} \mathrm{SO}_{4} \cdot 10 \mathrm{H}_{2} \mathrm{O}$

\begin{tabular}{|c|l|c|c|c|}
\hline Crt. Nr. & Hydrogel type & a & b & $\mathbf{R}^{2}$ \\
\hline 1 & PVA/ $\mathrm{H}_{2} \mathrm{O}$ & 0.2050 & -2.3234 & 0.9972 \\
\hline 2 & $\mathrm{PVA} / \mathrm{Na}_{2} \mathrm{SO}_{4} / \mathrm{H}_{2} \mathrm{O}$ & 0.2441 & -2.4896 & 0.9942 \\
\hline 3 & $\mathrm{PVA} / \mathrm{NaCl} / \mathrm{H}_{2} \mathrm{O}$ & 0.2406 & -2.5905 & 0.9841 \\
\hline 4 & $\mathrm{PVA} / \mathrm{NaNO}_{3} / \mathrm{H}_{2} \mathrm{O}$ & 0.2147 & -2.5860 & 0.9926 \\
\hline
\end{tabular}

ing PVA solution. As we reported in other papers [37], the crystallinity of the cryogels is highly influenced by the initial PVA solution concentration. All the salts used for the preparation of the saltbased PVA cryogels determined their crystallinity increase, and, therefore, the increase of the $n$ values, describing the water diffusion from more rigid (crystalline) structures. From this point of view, the hierarchy of the salts is the same, determined by checking their influence on the other properties of the cryogels.

In agreement with the former results, the rate of the water release is higher for the gels having higher crystallinity due to the lower interaction of the polymer chains with the water molecules, and it decreases for lower crystalline cryogels, due to the higher interaction of the water molecules with the polymer $\mathrm{OH}$ groups that are not involved in the crystallization process.

The order of the water release rates follows the same rule found for the other properties:

$\mathrm{PVA} / \mathrm{Na}_{2} \mathrm{SO}_{4} / \mathrm{H}_{2} \mathrm{O}(1.83 \% / \mathrm{min})>\mathrm{PVA} / \mathrm{H}_{2} \mathrm{O}$ $(1.82 \% / \mathrm{min})>\mathrm{PVA} / \mathrm{NaCl} / \mathrm{H}_{2} \mathrm{O}(1.30 \% / \mathrm{min})>$ $\mathrm{PVA} / \mathrm{NaNO}_{3} / \mathrm{H}_{2} \mathrm{O}(0.98 \% / \mathrm{min})$.

\section{Conclusions}

PVA cryogels are ecological materials, biodegradable, biocompatible, non-toxic and non-carcinogenic, with very large domains of application. Any method that could be helpful in the PVA cryogels properties tailoring is important because it could enlarge its application fields.

The salts addition to the PVA aqueous solution, before submitting it to the repeated freezing-thawing cycles for the cryogels obtaining, is one of the simplest methods that allow the modification of the hydrogel properties.

The data reported in this paper show that the ions present in the PVA solution influence the interac- 
tion between PVA-water and PVA-PVA chains, leading to the obtaining of cryogels with different crystallinity and porosity. The ion influence follows the Hofmeister lyotropic series: kosmotropic anions determine higher cryogels crystallinity and compactity while chaotropic anions determine higher amorphous and more porous cryogels obtaining. As consequence, the cryogel properties such as: transparency, EWC, capacity to collapse in the presence of electrolytes solutions, the collapse rate, the collapse mechanism, and rheological properties could be modified by adding different salts to the initial PVA solution.

\section{Acknowledgements}

Authors would like to thank to Romanian National Project IDEI-839/ 2009 for funding this research.

\section{References}

[1] Paţachia S.: Blends based on poly(vinyl alcohol) and the products based on this polymer. in: 'Handbook of polymer blends and composites' (eds.: Vasile C., Kulshreshtha A. K.) Rapra Technology, Shawbury, 288365 (2003).

[2] Hennink W. E., van Nostrum C. F.: Novel crosslinking methods to design hydrogels. Advanced Drug Delivery Reviews, 54, 13-36 (2002). DOI: $10.1016 / \mathrm{S} 0169-409 \mathrm{X}(01) 00240-\mathrm{X}$

[3] Peppas N. A., Bures P., Leobandung W., Ichikawa H.: Hydrogels in pharmaceutical formulations. European Journal of Pharmaceutics and Biopharmaceutics, 50, 27-46 (2000). DOI: $10.1016 / \mathrm{S} 0939-6411(00) 00090-4$

[4] Ratner B., Hoffman A. S., Schoen F. J., Lemons J. E.: Biomaterials science: An introduction to materials in medicine. Elsevier Academic Press, San Diego (2004).

[5] Hassan C. M., Peppas N. A.: Structure and applications of poly(vinyl alcohol) hydrogels produced by conventional crosslinking or by freezing-thawing methods. Advances in Polymer Science, 153, 37-65 (2000). DOI: $10.1007 / 3-540-46414-X$

[6] Hoffman A. S.: Hydrogels for biomedical applications. Annals of the New York Academy of Science, 944, 62-73 (2001).

[7] Werner B., Bu H. T., Kjonisken A-L., Sande S. A., Nyström B.: Characterization of gelation of aqueous pectin via the ugi multicomponent condensation reaction. Polymer Bulletin, 56, 579-589 (2006).

DOI: $10.1007 / \mathrm{s} 00289-006-0522-6$
[8] de Jong S. J., De Smedt S. C., Demeester J. M., van Nostrum C. F., Kettenes-van den Bosch J. J., Hennink W. E.: Biodegradable hydrogels based on stereocomplex formation between lactic acid oligomers grafted to dextran. Journal of Controlled Release, 72, 47-56 (2001). DOI: $10.1016 / \mathrm{S} 0168-3659(01) 00261-9$

[9] dos Reis E. F., Campos F. S., Lage A. P., Leite R. C., Heneine I. G., Vasconcelos W. L., Lobato Z. I. P., Mansur H. S.: Synthesis and characterization of poly (vinyl alcohol) hydrogels and hybrids for rMPB70 protein adsorption. Materials Research, 9, 185-191 (2006).

DOI: $10.1590 / \mathrm{S} 1516-14392006000200014$

[10] Paţachia S., Valente A. J. M., Papancea A., Lobo V. M. M. V: Poly(vinyl alcohol) [PVA]-based polymer membranes: Synthesis and applications. in 'Organic and Physical chemistry using chemical kinetics' (eds.: Medvedevskikh Y. G., Valente A., Howell R. A., Zaikov G. E.) Nova Publishers, New York, 103-166 (2007).

[11] Nuget M. J. D., Hanley A., Tomkins P. T., Higginbotham C. L.: Investigation of a novel freeze-thaw process for the production of drug delivery hydrogels. Journal of Materials Science: Materials in Medicine, 16, 1149-1158 (2005). DOI: $10.1007 / \mathrm{s} 10856-005-4722-7$

[12] Lozinsky V. I., Domotenko L. V., Zumbov A. L., Simenel I. A.: Study of cryostructuration of polymer systems. XII. Poly(vinyl alcohol) cryogels: Influence of low-molecular electrolytes. Journal of Applied Polymer Science, 61, 1991-1998 (1996).

DOI: $10.1002 /($ SICI) 1097-4628(19960912)61:11< 1991::AID-APP13>3.0.CO;2-2

[13] Iwaseya M., Katsuyama N., Yamaura K., Dai L-X.: Effect of degree saponification on the properties of films obtained from $\mathrm{PVA} / \mathrm{NaCl} / \mathrm{H}_{2} \mathrm{O}$ systems. Journal of Materials Science, 41, 1979-1982 (2006). DOI: 10.1007/s10853-006-3082-0

[14] Yamaura K., Naitoh M.: Preparation of high performance films from poly(vinyl alcohol) $/ \mathrm{NaCl} / \mathrm{H}_{2} \mathrm{O}$ systems. Journal of Materials Science, 37, 705-708 (2002).

[15] Iwaseya M., Watanabe M., Yamaura K., Dai L-X., Noguchi H.: High performance films obtained from $\mathrm{PVA} / \mathrm{Na}_{2} \mathrm{SO}_{4} / \mathrm{H}_{2} \mathrm{O}$ and PVA $/ \mathrm{CH}_{3} \mathrm{COOONa} / \mathrm{H}_{2} \mathrm{O}$ systems. Journal of Materials Science, 40, 5695-5698 (2005). DOI: $10.1007 / \mathrm{s} 10853-005-1429-6$

[16] Bhargav P. B., Mohan V. M., Sharma A. K., Rao V.: Structural and electrical studies of sodium iodide doped poly(vinyl alcohol) polymer electrolyte films for their application in electrochemical cells. Ionics, 13, 173-178 (2007). DOI: $10.1007 / \mathrm{s} 11581-007-0102-2$ 
[17] Bhajantri S. F., Ravindachary V., Harisha A., Ranganathaiah C., Kumaraswamy G. N.: Effect of barium chloride doping on PVA microstructure: Positron annihilation study. Applied Physics A: Materials Science and Processing, 87, 797-805 (2007).

DOI: $10.1007 / \mathrm{s} 00339-007-3923-y$

[18] Paţachia S., Valente A. J. M., Baciu C.: Effect of nonassociated electrolyte solutions on the behaviour of poly(vinyl alcohol)-based hydrogels. European Polymer Journal, 43, 460-467 (2007).

DOI: 10.1016/j.eurpolymj.2006.11.009

[19] Lozinsky V. I., Zubov A. L., Titova E. F.: Swelling behavior of poly(vinyl alcohol) cryogels employed as matrices for cell immobilization. Enzyme and Microbial Technology, 18, 561-569 (1996). DOI: $10.1016 / 0141-0229(95) 00148-4$

[20] Lozinsky V. I., Plieva F. M.: Poly(vinyl alcohol) cryogels employed as matrices for cell immobilization. 3 . Overview of recent research and developments. Enzyme and Microbial Technology, 23, 227-242 (1998). DOI: 10.1016/S0141-0229(98)00036-2

[21] Paţachia S., Baciu Florea C.: Poly(vinyl alcohol) hydrogels interaction with electrolytes in aqueous solution. Revue Roumaine de Chimie, 52, 1145-1149 (2007).

[22] Paţachia S., Florea C.: Poly(vinyl alcohol) cryogels: Investigations on their behaviour in aqueous electrolytes solutions. in 'Recent advances in research on biodegradable polymers and sustainable composites' (eds.: Jimenez A., Zaikov G.E.) Vol 3, 70-78, Nova Publisher, New York (2008).

[23] Kim J. J., Park K.: Smart hydrogels for bioseparation. Bioseparation, 7, 177-187 (1999).

[24] De S. K., Aluru N. L., Johnson B., Crone W. C., Beebe D. J., Moore J.: Equilibrium swelling and kinetics of pH-responsive hydrogels: Models, experiments, and simulations. Journal of Microelectromechanical Systems, 11, 544-555 (2002).

DOI: 10.1109/JMEMS.2002.803281

[25] Cha W-I., Hyon S. H., Ikada Y.: Transparent poly(vinyl alcohol) hydrogel with high water content and high strength. Die Makromolekulare Chemie, 193, 1913-1925 (2003). DOI: $10.1002 / \mathrm{macp} .1992 .021930812$

[26] Hassan C. M., Peppas N. A.: Cellular PVA hydrogels produced by freezing/thawing. Journal of Applied Polymer Science, 76, 2075-2079 (2000).

DOI: $10.1002 /($ SICI $) 1097-4628(20000628) 76: 14<$ 2075::AID-APP11>3.0.CO;2-V
[27] Mansur H. S., Sadahira C. M., Souza A. N., Mansur A. A. P.: FTIR spectroscopy characterization of poly(vinyl alcohol) hydrogel with different hydrolysis degree and chemically crosslinked with glutaraldehyde. Material Science and Engineering C: Biomimetic and Supramolecular Systems, 28, 539-548 (2008). DOI: $10.1016 /$ j.msec.2007.10.088

[28] Shaheen S. M., Ukai K., Dai L., Yamaura K.: Properties of hydrogels of atactic poly(vinyl alcohol)/ $\mathrm{NaCl} /$ $\mathrm{H}_{2} \mathrm{O}$ system and their application to drug delivery. Polymer International, 51, 1390-1397 (2002). DOI: $10.1002 / \mathrm{pi} .1061$

[29] Zhang Y., Cremer P. S.: Interactions between macromolecules and ions: The Hofmeister series. Current Opinion in Chemical Biology, 10, 658-663 (2006). DOI: $10.1016 /$ j.cbpa.2006.09.020

[30] Gurau M. C., Lim S-M., Castellana E. T., Albertorio F., Kataoka S., Cremer P. S.: On the mechanism of the Hofmeister effect. Journal of the American Chemical Society, 126, 10522-10523 (2004).

DOI: $\underline{10.1021 / \mathrm{ja} 047715 \mathrm{c}}$

[31] Omta A. W., Kropman M. F., Woutersen S., Bakker H. J.: Influence of ions on the hydrogel-bond structure in liquid water. Journal of Chemical Physics, 119, 12457-12461 (2003).

DOI: $10.1063 / 1.1623746$

[32] Saraydin D., Çaldiran Y.: In vitro dynamic swelling behaviors of polyhydroxamic acid hydrogels in the simulated physiological body fluids. Polymer Bulletin, 46, 91-98 (2001).

DOI: $10.1007 / \mathrm{s} 002890170093$

[33] Ahmad B., Bashir S., Nisa S., Huglin M. B.: Chemically crosslinked N-vynil-2-pyrrolidone/2-hydroxyethyl methacrylate (VP/HEMA) copolymer for controlled release of cyclic oligopeptide. Turkish Journal of Chemistry, 23, 279-285 (2004).

[34] Peppas N. A., Khare A. R.: Preparation, structure and diffusional behavior of hydrogels in controlled release. Advance Drug Delivery Reviews, 11, 1-35 (1993).

DOI: $\underline{10.1016 / 0169-409 X(93) 90025-Y}$

[35] Kim B., La Flamme K., Peppas N. A.: Dynamic swelling behavior of $\mathrm{pH}$-sensitive anionic hydrogels used for protein delivery. Journal of Applied Polymer Science, 89, 1606-1613 (2003).

DOI: $10.1002 /$ app. 12337

[36] Ji S., Ding J.: The wetting process of a dry polymeric hydrogel. Polymer Journal, 34, 267-270 (2002). DOI: $10.1295 /$ polymj. 34.267

[37] Paţachia S., Rînja M., Friedrich Chr.: Correlation between poly(vinyl alcohol) cryogel swelling capacity and synthesis parameters. in 'Recent advances in research on biodegradable polymers and sustainable composites' (eds.: Jimenez A., Zaikov G. E.) Vol 3, 130-138, Nova Publisher, New York (2008). 